\title{
Inhibiting Extracellular Vesicle Trafficking as Antiviral Approach to Corona Virus Disease 2019 Infection
}

\author{
Enrica Urciuoli and Barbara Peruzzi * \\ Multifactorial and Complex Diseases Research Area, Bambino Gesù Children's Hospital, IRCCS, Rome, Italy
}

Keywords: extracellular vesicles, exosomes, viruses, Severe Acute Respiratory Syndrome-Associated Coronavirus-2 infection, drug repurposing

\section{INTRODUCTION}

At the end of 2019, some pneumonia cases with unknown aetiology were reported by Chinese health authorities in the city of Wuhan (Hubei province, China). On 9 January 2020, a new coronavirus (provisionally named 2019-nCoV) was identified by the Chinese center for disease control and prevention as the causative agent for these pneumonias. On February 2020, the World Health Organization announced that the respiratory disease caused by $2019-\mathrm{nCoV}$ had been officially named COVID-19 (Corona Virus Disease 2019) and the virus responsible for the COVID-19 cases was classified and designated as SARS-CoV-2 (Coronaviridae Study Group of the International Committee on Taxonomy of Viruses, 2020). As of 3 July 2020, more than 10.7 million cases of COVID-19 have been reported in more than 213 countries, resulting in more than 500,000 deaths.

SARS-CoV-2 is a member of the family Coronaviridae. It is an enveloped virus with a positive RNA genome, whose infection is regulated by the binding between its membrane glycoprotein Spike and the angiotensin-converting enzyme 2 (ACE2) receptor on the host human cell surface (Li et al., 2005). Once inside the host cell, the viral replicase complexes are assembled, the viral RNA is synthetized, replicated and subsequently encapsidated resulting in the formation of the mature virus. Following assembly, virions are carried to the cell membrane into intracellular vesicles and released by exocytosis (Malik, 2020). To date there are not yet available vaccines and there is very little evidence about effective treatments, and primary treatment is symptomatic and supportive therapy.

\section{EXTRACELLULAR VESICLES AND VIRUSES SHARE COMMON FEATURES AND ENTRY ROUTES FOR CARGO DELIVERY}

Extracellular vesicles (EVs) are a heterogeneous group of vesicles containing proteins and nucleic acids derived from the cell of origin and released by mammalian cells under physiological and pathological conditions (Yuana et al., 2013). EVs are typically classified according to their dimension and the biogenesis processes by which they originate in exosomes (size range: 30-150 nm) (Huotari and Helenius, 2011), microvesicles (size range: 100-1000 nm) (Muralidharan-Chari et al., 2010), 
and apoptotic bodies. It is worth noting that EVs participate to virus infection and that numerous cellular components involved in EV biogenesis are required for the virion biogenesis.

Nolte-'t Hoena and coauthors assert that, when enveloped RNA viruses infect target cells, these cells are able to release a variety of vesicles containing host and viral factors (Nolte-'t et al., 2016). Therefore, it could be helpful to compare virus particles and EVs in order to improve understanding of both viral life cycles and the function of EVs. Indeed, both viruses and EVs have size ranging from $\leq 100 \mathrm{~nm}$ to $>1000 \mathrm{~nm}$ and have similar biochemical composition and biophysical properties (RaabTraub and Dittmer, 2017). In particular, Coronaviruses are approximately $125 \mathrm{~nm}$ in diameter (Neuman et al., 2006; Barcena et al., 2009), as well as the exosomes, the largest EV subpopulation with a $<300 \mathrm{~nm}$ size. Enveloped viruses and EVs contain proteins and nucleic acids, as well as they share pathway for fusion into host cells and for biogenesis at the plasma membrane (Figure 1).

In order to bind their favorite host tissue cells, viruses usually recognize cell-surface receptors that have pivotal roles in cell physiology. EVs are able to transfer those receptors needed by viruses for fusing on target cells to receptor-null cells, thereby increasing the amount of cells to infect (Hassanpour et al., 2020). Among the cellular receptors exploited to start viral infection, integrins have been usurped by non-enveloped and enveloped viruses for attachment and/or cell entry (Hussein et al., 2015). Sigrist and coauthors suggest that the SARS-CoV-2 spike (S) protein show a RGD motif known to bind integrins, thereby hypothesizing that integrin may act as an alternative receptor for SARS-CoV-2, other than ACE2 receptor-binding region, and could be implicated in its transmission and pathology (Sigrist et al., 2020). In the same way as viruses, circulating EVs can bind to the cell membrane of target cells exploiting the presence of several adhesion molecules, among which integrins and cell adhesion molecules (Thery et al., 1999; Clayton et al., 2004; Mathivanan et al., 2012; Kim et al., 2013; Kim et al., 2015).
In this context, noteworthy is the involvement of tetraspanins, a superfamily of transmembrane glycoproteins whose members appear to form complexes (also called tetraspanin-enriched microdomains or TEMs) by their association with several transmembrane and intracellular signaling/cytoskeletal proteins (Hemler, 2003).

EVs are known to be enriched in tetraspanins (Escola et al., 1998; Lokossou et al., 2014; Hurwitz et al., 2018), at a such extent that they are often used as exosome biomarkers. As regarding EV uptake, the adhesion molecules involved in the EV binding to target cell are commonly inserted in TEMs (Barreiro et al., 2005). TEMs seem to represent an alternative route of endocytosis, other than the dominant phagocytic processes and clathrin-dynamin-caveolaedependent endocytosis, in exosome internalization or fusion (Andreu and Yanez-Mo, 2014). Parallelly, data from the literature indicates that specific tetraspanin family members are selectively associated with specific viruses and affect multiple stages of infection, from initial cellular attachment to syncytium formation and viral particle release (Martin et al., 2005). Interestingly, Earnest and coauthors demonstrated that coronavirus proteolytic priming takes place in TEM microdomains (Earnest et al., 2015), suggesting that blocking tetraspanin functions by antibodies inhibits $\mathrm{CoV}$ infection.

Followed the entry, viruses and EVs are able to change functions of the recipient cells by carrying proteic and genetic material into target cells (Valadi et al., 2007; Yanez-Mo et al., 2015; Gilbert and Cordaux, 2017; Urciuoli et al., 2018).

Over time the relationship between viruses and EVs has been addressed. Early discussions highlighted that both EVs and retroviruses are able to release vesicles (Gould et al., 2003; Pelchen-Matthews et al., 2004), showing striking similarities in lipid composition and protein content. The "Trojan exosome hypothesis" was based on the fact that retroviruses exploit preexisting pathways to spread viral vesicles (Gould et al., 2003), and, at the same time, there was evidence about the capability of EVs to modify target cells transferring proteins, lipids, and genetic material (Pelchen-Matthews et al., 2004).

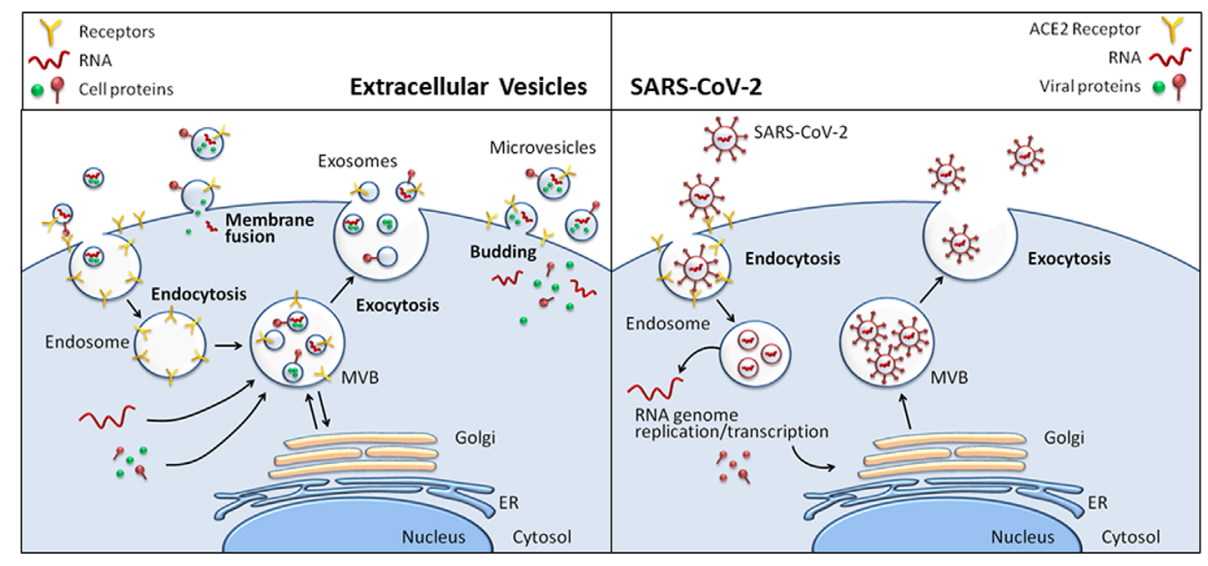

FIGURE 1 | Comparison between Extracellular Vesicle and virion biogenesis at the plasma membrane in eukaryotic cells. 
Recently, it has been proposed that in order to infect target cells, viruses may adopt existing EV-mediated communication pathways (Izquierdo-Useros et al., 2011) by using, for example, the phosphatidylserine receptors to entry into cells. (Grove and Marsh, 2011; Moller-Tank et al., 2013). Exosomes convey phosphatidylserine groups on their surface (Miyanishi et al., 2007; Feng et al., 2010), thus representing one of the shared targeting mechanisms between exosomes and viruses.

EVs released during viral infection may have either positive or negative effects. In the case of enveloped viruses, EVs participate in viral pathogenesis by containing selected molecules of viral origin (Chahar et al., 2015) or by increasing the number of activated cells or their responsiveness to viral infection (He et al., 2010; Narayanan et al., 2013; Arenaccio et al., 2014). In other cases, EVs serve as decoys that absorb antiviral antibodies, thereby compromising antiviral immunity (de Carvalho et al., 2014). On the other hand, viral-derived EVs alert dendritic cells with viral antigens to trigger adaptive immune responses (Dreux et al., 2012; Bernard et al., 2014).

\section{REPURPOSING OF DRUGS INHIBITING EV TRAFFICKING TO COUNTERACT COVID- 19 INFECTION}

Basing on all these considerations on virus and EV similarities, in our opinion the use of pharmacological EV inhibitors could represents an important antiviral approach acting at two different levels: first, inhibiting EV trafficking could be useful in inhibiting virus budding; second, since EVs generated by infected cells participate to viral infection, the inhibition of "viral" EV release should interfere with virus systemic spreading. EVs inhibitors are clustered in EV trafficking inhibitors and lipid metabolism inhibitors (Catalano and O’Driscoll, 2020).

\section{EV Trafficking Inhibitors}

Calpeptin blocks calpains, a family calcium-dependent cysteine proteases involved in different cellular processes including microvesicles shedding. Calpeptin has been demonstrated to reduce microvesicle production by activated platelets (Fox et al., 1991; Crespin et al., 2009; Mallick et al., 2015), HEK293 cells (Atanassoff et al., 2014), and PC3 cell line (Jorfi et al., 2015), and to be effective in inhibiting Severe Acute Respiratory Syndrome-Associated Coronavirus (SARSCoV) replication in vitro (Barnard et al., 2004).

Manumycin A is a Ras activity inhibitor. Ras is a family of small GTPases involves in several key cellular processes among which exosomes release (Wennerberg et al., 2005). Hyun Jeong $\mathrm{Oh}$ and coworkers have demonstrated that manumycin treatment reduced the amount of CD63-bearing exosomes A in F11 cells (Oh et al., 2017). Moreover, the effects of manumycin A on exosomes production have been also reported in prostate cancer cells and during wound healing process (Datta et al., 2017; Zhou et al., 2017).
Y27632 is a competitive inhibitor of both ROCK1 and ROCK2, serine-threonine kinases involved in cytoskeleton reorganization. RhoA/ROCK signaling have a fundamental role in microvesicle formation ( $\mathrm{Li}$ et al., 2012). This inhibitor has been used to treat different types of endothelial cell lines decreasing the amount of EVs released (Tramontano et al., 2004; Sapet et al., 2006; Abid Hussein et al., 2007; Latham et al., 2013; Kim et al., 2014). Moreover, Zhang and coauthors have recently highlighted the role of microvesicles in lung inflammation (Zhang et al., 2018) and, more recently, the same authors described that RhoA inhibitor Y27632 suppresses microvesicles production and alleviates lung inflammatory (Dai et al., 2019). These findings are very encouraging in terms of EVbased pharmacologic approach to COVID-19. Indeed in the last months Abedi et al. reviewed the therapeutic role of Rho kinases inhibitors in acute lung injury (Abedi et al., 2020a), proposing them as a possible therapy against SARS-CoV-2 (Abedi et al., 2020b).

\section{Lipid Metabolism Inhibitors}

Pantethine has been demonstrated to inhibit cholesterol as well as total fatty acids synthesis (Ranganathan et al., 1982), thereby affecting microvesicle release in breast cancer cells (Roseblade et al., 2015) and in endothelial cells infected by Plasmodium berghei ANKA (Penet et al., 2008). Moreover, by using molecular docking analysis, Verma and coauthors suggest pantethine among the FDA approved drugs that could potentially bind to the substrate-binding site and inhibit SARS-CoV-2 main protease (preprint available: doi:10.20944/preprints202004.0149.v1).

Imipramine has inhibitory activity on acid sphingomyelinases, enzymes that allow the hydrolysis of sphingomyelin to ceramide by a process that permits to increase membrane fluidity, exosome release and microvesicle generation (Arenz, 2010). The effects of Imipramine have been evaluated in microvesicles derived from microglia cells (Bianco et al., 2009), osteoblast cells (Deng et al., 2017) and PC3 cell line (Kosgodage et al., 2017). Moreover, since SARS-CoV-2 seems to exploit macropinocytosis at multiple stages in its replication, Imipramine, as a macropinocytosis inhibitor, could be considered a candidate repurposed as therapeutic agents for the treatment of COVID-19 (Lin et al., 2018).

GW4869 is a potent, specific non-competitive inhibitor of membrane neutral sphingomyelinase and its activity on exosome production was studied in cardiac fibroblasts (Lyu et al., 2015), cancer-associated fibroblasts (CAF) in colorectal cancer (Hu et al., 2015), hepatic stellate cells involved in chronic liver injury (Charrier et al., 2014) and melanoma (Matsumoto et al., 2017).

\section{DISCUSSION}

Viruses exploit most of the cell machinery aimed at producing and releasing EVs, which in turn seem to be crucial components in the pathogenesis of virus infection. Therefore, we here proposed the feasibility to use EV trafficking inhibitors as a valuable therapeutic approach to counteract virus infections, 
among which the current SARS-CoV-2 outbreak. EV inhibitors have been used in several in vitro studies, and some FDAapproved drugs are commonly used in a large spectrum of human diseases. Moreover, it is worth to note that the rationale to block EV production in infected cells has been already explored, i.e. Huang et al. used GW4869 to suppress Zika virus propagation blocking neutral sphingomielinase-2 (Huang et al., 2018) and Pegtel and coauthors studied the effects of Dynasore to inhibit exosome endocytosis in EBVinfected cells (Pegtel et al., 2010). Moreover, Raab-Traub and Dittmer demonstrated that cells infected by viruses release more EVs than virion (Raab-Traub and Dittmer, 2017), further supporting our opinion that the EV pathway could be inhibited to counteract virus infection and spreading, thereby

\section{REFERENCES}

Abedi, F., Hayes, A. W., Reiter, R., and Karimi, G. (2020a). Acute lung injury: The therapeutic role of Rho kinase inhibitors. Pharmacol. Res. 155, 104736. doi: 10.1016/j.phrs.2020.104736

Abedi, F., Rezaee, R., and Karimi, G. (2020b). Plausibility of therapeutic effects of Rho kinase inhibitors against Severe Acute Respiratory Syndrome Coronavirus 2 (COVID-19). Pharmacol. Res. 156, 104808. doi: 10.1016/ j.phrs.2020.104808

Abid Hussein, M. N., Boing, A. N., Sturk, A., Hau, C. M., and Nieuwland, R. (2007). Inhibition of microparticle release triggers endothelial cell apoptosis and detachment. Thromb. Haemost. 98, 1096-1107. doi: 10.1160/TH05-040231

Andreu, Z., and Yanez-Mo, M. (2014). Tetraspanins in extracellular vesicle formation and function. Front. Immunol. 5:442. doi: 10.3389/fimmu. 2014.00442

Arenaccio, C., Chiozzini, C., Columba-Cabezas, S., Manfredi, F., Affabris, E., Baur, A., et al. (2014). Exosomes from human immunodeficiency virus type 1 (HIV-1)infected cells license quiescent CD4+ T lymphocytes to replicate HIV-1 through a Nef- and ADAM17-dependent mechanism. J. Virol. 88, 11529-11539. doi: 10.1128/JVI.01712-14

Arenz, C. (2010). Small molecule inhibitors of acid sphingomyelinase. Cell Physiol. Biochem. 26, 1-8. doi: 10.1159/000315100

Atanassoff, A. P., Wolfmeier, H., Schoenauer, R., Hostettler, A., Ring, A., Draeger, A., et al. (2014). Microvesicle shedding and lysosomal repair fulfill divergent cellular needs during the repair of streptolysin O-induced plasmalemmal damage. PLoS One 9, e89743. doi: 10.1371/journal.pone.0089743

Barcena, M., Oostergetel, G. T., Bartelink, W., Faas, F. G., Verkleij, A., Rottier, P. J., et al. (2009). Cryo-electron tomography of mouse hepatitis virus: Insights into the structure of the coronavirion. Proc. Natl. Acad. Sci. U. S. A. 106, 582-587. doi: 10.1073/pnas.0805270106

Barnard, D. L., Hubbard, V. D., Burton, J., Smee, D. F., Morrey, J. D., Otto, M. J., et al. (2004). Inhibition of severe acute respiratory syndromeassociated coronavirus (SARSCoV) by calpain inhibitors and beta-D-N4hydroxycytidine. Antivir. Chem. Chemother. 15, 15-22. doi: 10.1177/ 095632020401500102

Barreiro, O., Yanez-Mo, M., Sala-Valdes, M., Gutierrez-Lopez, M. D., Ovalle, S., Higginbottom, A., et al. (2005). Endothelial tetraspanin microdomains regulate leukocyte firm adhesion during extravasation. Blood 105, 2852-2861. doi: 10.1182/blood-2004-09-3606

Bernard, M. A., Zhao, H., Yue, S. C., Anandaiah, A., Koziel, H., and Tachado, S. D. (2014). Novel HIV-1 miRNAs stimulate TNFalpha release in human macrophages via TLR8 signaling pathway. PLoS One 9, e106006. doi: 10.1371/journal.pone.0106006

Bianco, F., Perrotta, C., Novellino, L., Francolini, M., Riganti, L., Menna, E., et al. (2009). Acid sphingomyelinase activity triggers microparticle release from glial cells. EMBO J. 28, 1043-1054. doi: 10.1038/emboj.2009.45 being potentially effective as a therapeutic approach to COVID19 pandemic.

\section{AUTHOR CONTRIBUTIONS}

EU and BP contributed equally, conceptualized the paper, wrote the manuscript, read, edited, and approved the submitted version.

\section{FUNDING}

This study was supported by a grant from the Italian Ministry of Health ("Ricerca corrente") to B.P.

Catalano, M., and O'Driscoll, L. (2020). Inhibiting extracellular vesicles formation and release: a review of EV inhibitors. J. Extracell. Vesicles 9, 1703244. doi: 10.1080/20013078.2019.1703244

Chahar, H. S., Bao, X., and Casola, A. (2015). Exosomes and Their Role in the Life Cycle and Pathogenesis of RNA Viruses. Viruses 7, 3204-3225. doi: 10.3390/ v7062770

Charrier, A., Chen, R., Chen, L., Kemper, S., Hattori, T., Takigawa, M., et al. (2014). Exosomes mediate intercellular transfer of pro-fibrogenic connective tissue growth factor (CCN2) between hepatic stellate cells, the principal fibrotic cells in the liver. Surgery 156, 548-555. doi: 10.1016/j.surg.2014.04.014

Clayton, A., Turkes, A., Dewitt, S., Steadman, R., Mason, M. D., and Hallett, M. B. (2004). Adhesion and signaling by B cell-derived exosomes: the role of integrins. FASEB J. 18, 977-979. doi: 10.1096/fj.03-1094fje

Coronaviridae Study Group of the International Committee on Taxonomy of Viruses (2020). The species Severe acute respiratory syndrome-related coronavirus: classifying 2019-nCoV and naming it SARS-CoV-2. Nat. Microbiol. 5, 536-544. doi: 10.1038/s41564-020-0695-Z

Crespin, M., Vidal, C., Picard, F., Lacombe, C., and Fontenay, M. (2009). Activation of PAK1/2 during the shedding of platelet microvesicles. Blood Coagul. Fibrinol. 20, 63-70. doi: 10.1097/MBC.0b013e32831bc310

Dai, H., Zhang, S., Du, X., Zhang, W., Jing, R., Wang, X., et al. (2019). RhoA inhibitor suppresses the production of microvesicles and rescues high ventilation induced lung injury. Int. Immunopharmacol. 72, 74-81. doi: 10.1016/j.intimp.2019.03.059

Datta, A., Kim, H., Lal, M., McGee, L., Johnson, A., Moustafa, A. A., et al. (2017). Manumycin A suppresses exosome biogenesis and secretion via targeted inhibition of Ras/Raf/ERK1/2 signaling and hnRNP H1 in castrationresistant prostate cancer cells. Cancer Lett. 408, 73-81. doi: 10.1016/ j.canlet.2017.08.020

de Carvalho, J. V., de Castro, R. O., da Silva, E. Z., Silveira, P. P., Silva-Januario, M. E., Arruda, E., et al. (2014). Nef neutralizes the ability of exosomes from CD4+ $\mathrm{T}$ cells to act as decoys during HIV-1 infection. PLoS One 9, e113691. doi: 10.1371/journal.pone.0113691

Deng, L., Peng, Y., Jiang, Y., Wu, Y., Ding, Y., Wang, Y., et al. (2017). Imipramine Protects against Bone Loss by Inhibition of Osteoblast-Derived Microvesicles. Int. J. Mol. Sci. 18, 1013. doi: 10.3390/ijms18051013

Dreux, M., Garaigorta, U., Boyd, B., Decembre, E., Chung, J., Whitten-Bauer, C., et al. (2012). Short-range exosomal transfer of viral RNA from infected cells to plasmacytoid dendritic cells triggers innate immunity. Cell Host. Microbe 12, 558-570. doi: 10.1016/j.chom.2012.08.010

Earnest, J. T., Hantak, M. P., Park, J. E., and Gallagher, T. (2015). Coronavirus and influenza virus proteolytic priming takes place in tetraspanin-enriched membrane microdomains. J. Virol. 89, 6093-6104. doi: 10.1128/JVI.00543-15

Escola, J. M., Kleijmeer, M. J., Stoorvogel, W., Griffith, J. M., Yoshie, O., and Geuze, H. J. (1998). Selective enrichment of tetraspan proteins on the internal vesicles of multivesicular endosomes and on exosomes secreted by human Blymphocytes. J. Biol. Chem. 273, 20121-20127. doi: 10.1074/jbc.273.32.20121 
Feng, D., Zhao, W. L., Ye, Y. Y., Bai, X. C., Liu, R. Q., Chang, L. F., et al. (2010). Cellular internalization of exosomes occurs through phagocytosis. Traffic 11, 675-687. doi: 10.1111/j.1600-0854.2010.01041.x

Fox, J. E., Austin, C. D., Reynolds, C. C., and Steffen, P. K. (1991). Evidence that agonist-induced activation of calpain causes the shedding of procoagulantcontaining microvesicles from the membrane of aggregating platelets. J. Biol. Chem. 266, 13289-13295.

Gilbert, C., and Cordaux, R. (2017). Viruses as vectors of horizontal transfer of genetic material in eukaryotes. Curr. Opin. Virol. 25, 16-22. doi: 10.1016/ j.coviro.2017.06.005

Gould, S. J., Booth, A. M., and Hildreth, J. E. (2003). The Trojan exosome hypothesis. Proc. Natl. Acad. Sci. U. S. A. 100, 10592-10597. doi: 10.1073/ pnas. 1831413100

Grove, J., and Marsh, M. (2011). The cell biology of receptor-mediated virus entry. J. Cell Biol. 195, 1071-1082. doi: 10.1083/jcb.201108131

Hassanpour, M., Rezaie, J., Nouri, M., and Panahi, Y. (2020). The role of extracellular vesicles in COVID-19 virus infection. Infect. Genet. Evol. 85, 104422. doi: 10.1016/j.meegid.2020.104422

He, N., Liu, M., Hsu, J., Xue, Y., Chou, S., Burlingame, A., et al. (2010). HIV-1 Tat and host AFF4 recruit two transcription elongation factors into a bifunctional complex for coordinated activation of HIV-1 transcription. Mol. Cell 38, 428438. doi: 10.1016/j.molcel.2010.04.013

Hemler, M. E. (2003). Tetraspanin proteins mediate cellular penetration, invasion, and fusion events and define a novel type of membrane microdomain. Annu. Rev. Cell Dev. Biol. 19, 397-422. doi: 10.1146/annurev.cellbio.19.111301.153609

Hu, Y., Yan, C., Mu, L., Huang, K., Li, X., Tao, D., et al. (2015). Fibroblast-Derived Exosomes Contribute to Chemoresistance through Priming Cancer Stem Cells in Colorectal Cancer. PLoS One 10, e0125625. doi: 10.1371/journal.pone. 0125625

Huang, Y., Li, Y., Zhang, H., Zhao, R., Jing, R., Xu, Y., et al. (2018). Zika virus propagation and release in human fetal astrocytes can be suppressed by neutral sphingomyelinase-2 inhibitor GW4869. Cell Discovery 4, 19. doi: 10.1038/ s41421-018-0017-2

Huotari, J., and Helenius, A. (2011). Endosome maturation. EMBO J. 30, 34813500. doi: 10.1038/emboj.2011.286

Hurwitz, S. N., Cheerathodi, M. R., Nkosi, D., York, S. B., and Meckes, D. G.Jr. (2018). Tetraspanin CD63 Bridges Autophagic and Endosomal Processes To Regulate Exosomal Secretion and Intracellular Signaling of Epstein-Barr Virus LMP1. J. Virol. 92, e01969-17. doi: 10.1128/JVI.01969-17

Hussein, H. A., Walker, L. R., Abdel-Raouf, U. M., Desouky, S. A., Montasser, A. K., and Akula, S. M. (2015). Beyond RGD: virus interactions with integrins. Arch. Virol. 160, 2669-2681. doi: 10.1007/s00705-015-2579-8

Izquierdo-Useros, N., Puertas, M. C., Borras, F. E., Blanco, J., and MartinezPicado, J. (2011). Exosomes and retroviruses: the chicken or the egg? Cell Microbiol. 13, 10-17. doi: 10.1111/j.1462-5822.2010.01542.x

Jorfi, S., Ansa-Addo, E. A., Kholia, S., Stratton, D., Valley, S., Lange, S., et al. (2015). Inhibition of microvesiculation sensitizes prostate cancer cells to chemotherapy and reduces docetaxel dose required to limit tumor growth in vivo. Sci. Rep. 5, 13006. doi: 10.1038/srep13006

Kim, D. K., Kang, B., Kim, O. Y., Choi, D. S., Lee, J., Kim, S. R., et al. (2013). EVpedia: an integrated database of high-throughput data for systemic analyses of extracellular vesicles. J. Extracell. Vesicles 2. doi: 10.3402/jev.v2i0.20384

Kim, M., Ham, A., Kim, K. Y., Brown, K. M., and Lee, H. T. (2014). The volatile anesthetic isoflurane increases endothelial adenosine generation via microparticle ecto-5'-nucleotidase (CD73) release. PLoS One 9, e99950. doi: 10.1371/journal.pone.0099950

Kim, D. K., Lee, J., Kim, S. R., Choi, D. S., Yoon, Y. J., Kim, J. H., et al. (2015). EVpedia: a community web portal for extracellular vesicles research. Bioinformatics 31, 933-939. doi: 10.1093/bioinformatics/btu741

Kosgodage, U. S., Trindade, R. P., Thompson, P. R., Inal, J. M., and Lange, S. (2017). Chloramidine/Bisindolylmaleimide-I-Mediated Inhibition of Exosome and Microvesicle Release and Enhanced Efficacy of Cancer Chemotherapy. Int. J. Mol. Sci. 18. doi: 10.3390/ijms18051007

Latham, S. L., Chaponnier, C., Dugina, V., Couraud, P. O., Grau, G. E., and Combes, V. (2013). Cooperation between beta- and gamma-cytoplasmic actins in the mechanical regulation of endothelial microparticle formation. FASEB J. 27, 672-683. doi: 10.1096/fj.12-216531
Li, F., Li, W., Farzan, M., and Harrison, S. C. (2005). Structure of SARS coronavirus spike receptor-binding domain complexed with receptor. Science 309, 1864-1868. doi: 10.1126/science.1116480

Li, B., Antonyak, M. A., Zhang, J., and Cerione, R. A. (2012). RhoA triggers a specific signaling pathway that generates transforming microvesicles in cancer cells. Oncogene 31, 4740-4749. doi: 10.1038/onc.2011.636

Lin, H. P., Singla, B., Ghoshal, P., Faulkner, J. L., Cherian-Shaw, M., O'Connor, P. M., et al. (2018). Identification of novel macropinocytosis inhibitors using a rational screen of Food and Drug Administration-approved drugs. Br. $J$ Pharmacol. 175, 3640-3655. doi: 10.1111/bph.14429

Lokossou, A. G., Toudic, C., and Barbeau, B. (2014). Implication of human endogenous retrovirus envelope proteins in placental functions. Viruses 6, 4609-4627. doi: 10.3390/v6114609

Lyu, L., Wang, H., Li, B., Qin, Q., Qi, L., Nagarkatti, M., et al. (2015). A critical role of cardiac fibroblast-derived exosomes in activating renin angiotensin system in cardiomyocytes. J. Mol. Cell Cardiol. 89, 268-279. doi: 10.1016/ j.yjmcc.2015.10.022

Malik, Y. A. (2020). Properties of Coronavirus and SARS-CoV-2. Malays. J. Pathol. 42, 3-11.

Mallick, R. L., Kumari, S., Singh, N., Sonkar, V. K., and Dash, D. (2015). Prion protein fragment (106-126) induces prothrombotic state by raising platelet intracellular calcium and microparticle release. Cell Calcium 57, 300-311. doi: 10.1016/j.ceca.2015.02.002

Martin, F., Roth, D. M., Jans, D. A., Pouton, C. W., Partridge, L. J., Monk, P. N., et al. (2005). Tetraspanins in viral infections: a fundamental role in viral biology? J. Virol. 79, 10839-10851. doi: 10.1128/JVI.79.17.10839-10851.2005

Mathivanan, S., Fahner, C. J., Reid, G. E., and Simpson, R. J. (2012). ExoCarta 2012: database of exosomal proteins, RNA and lipids. Nucleic Acids Res. 40, D1241-D1244. doi: 10.1093/nar/gkr828

Matsumoto, A., Takahashi, Y., Nishikawa, M., Sano, K., Morishita, M., Charoenviriyakul, C., et al. (2017). Accelerated growth of B16BL6 tumor in mice through efficient uptake of their own exosomes by B16BL6 cells. Cancer Sci. 108, 1803-1810. doi: 10.1111/cas.13310

Miyanishi, M., Tada, K., Koike, M., Uchiyama, Y., Kitamura, T., and Nagata, S. (2007). Identification of Tim4 as a phosphatidylserine receptor. Nature 450, 435-439. doi: 10.1038/nature06307

Moller-Tank, S., Kondratowicz, A. S., Davey, R. A., Rennert, P. D., and Maury, W. (2013). Role of the phosphatidylserine receptor TIM-1 in enveloped-virus entry. J. Virol. 87, 8327-8341. doi: 10.1128/JVI.01025-13

Muralidharan-Chari, V., Clancy, J. W., Sedgwick, A., and D'Souza-Schorey, C. (2010). Microvesicles: mediators of extracellular communication during cancer progression. J. Cell Sci. 123, 1603-1611. doi: 10.1242/jcs.064386

Narayanan, A., Iordanskiy, S., Das, R., Van Duyne, R., Santos, S., Jaworski, E., et al. (2013). Exosomes derived from HIV-1-infected cells contain trans-activation response element RNA. J. Biol. Chem. 288, 20014-20033. doi: 10.1074/ jbc.M112.438895

Neuman, B. W., Adair, B. D., Yoshioka, C., Quispe, J. D., Orca, G., Kuhn, P., et al. (2006). Supramolecular architecture of severe acute respiratory syndrome coronavirus revealed by electron cryomicroscopy. J. Virol. 80, 7918-7928. doi: 10.1128/JVI.00645-06

Nolte-'t, H. E., Cremer, T., Gallo, R. C., and Margolis, L. B. (2016). Extracellular vesicles and viruses: Are they close relatives? Proc. Natl. Acad. Sci. U. S. A. 113, 9155-9161. doi: 10.1073/pnas.1605146113

Oh, H. J., Shin, Y., Chung, S., Hwang, D. W., and Lee, D. S. (2017). Convective exosome-tracing microfluidics for analysis of cell-non-autonomous neurogenesis. Biomaterials 112, 82-94. doi: 10.1016/j.biomaterials.2016.10.006

Pegtel, D. M., Cosmopoulos, K., Thorley-Lawson, D. A., van Eijndhoven, M. A., Hopmans, E. S., Lindenberg, J. L., et al. (2010). Functional delivery of viral miRNAs via exosomes. Proc. Natl. Acad. Sci. U. S. A. 107, 6328-6333. doi: 10.1073/pnas.0914843107

Pelchen-Matthews, A., Raposo, G., and Marsh, M. (2004). Endosomes, exosomes and Trojan viruses. Trends Microbiol. 12, 310-316. doi: 10.1016/ j.tim.2004.05.004

Penet, M. F., Abou-Hamdan, M., Coltel, N., Cornille, E., Grau, G. E., de Reggi, M., et al. (2008). Protection against cerebral malaria by the low-molecular-weight thiol pantethine. Proc. Natl. Acad. Sci. U. S. A. 105, 1321-1326. doi: 10.1073/ pnas.0706867105 
Raab-Traub, N., and Dittmer, D. P. (2017). Viral effects on the content and function of extracellular vesicles. Nat. Rev. Microbiol. 15, 559-572. doi: 10.1038/nrmicro.2017.60

Ranganathan, S., Jackson, R. L., and Harmony, J. A. (1982). Effect of pantethine on the biosynthesis of cholesterol in human skin fibroblasts. Atherosclerosis 44, 261-273. doi: 10.1016/0021-9150(82)90002-8

Roseblade, A., Luk, F., Ung, A., and Bebawy, M. (2015). Targeting microparticle biogenesis: a novel approach to the circumvention of cancer multidrug resistance. Curr. Cancer Drug Targets 15, 205-214. doi: 10.2174/156800961 5666150225121508

Sapet, C., Simoncini, S., Loriod, B., Puthier, D., Sampol, J., Nguyen, C., et al. (2006). Thrombin-induced endothelial microparticle generation: identification of a novel pathway involving ROCK-II activation by caspase-2. Blood 108, 1868-1876. doi: 10.1182/blood-2006-04-014175

Sigrist, C. J., Bridge, A., and Le Mercier, P. (2020). A potential role for integrins in host cell entry by SARS-CoV-2. Antiviral Res. 177, 104759. doi: 10.1016/ j.antiviral.2020.104759

Thery, C., Regnault, A., Garin, J., Wolfers, J., Zitvogel, L., Ricciardi-Castagnoli, P., et al. (1999). Molecular characterization of dendritic cell-derived exosomes. Selective accumulation of the heat shock protein hsc73. J. Cell Biol. 147, 599610. doi: $10.1083 /$ jcb.147.3.599

Tramontano, A. F., O’Leary, J., Black, A. D., Muniyappa, R., Cutaia, M. V., and El Sherif, N. (2004). Statin decreases endothelial microparticle release from human coronary artery endothelial cells: implication for the Rho-kinase pathway. Biochem. Biophys. Res. Commun. 320, 34-38. doi: 10.1016/j.bbrc.2004.05.127

Urciuoli, E., Giorda, E., Scarsella, M., Petrini, S., and Peruzzi, B. (2018). Osteosarcoma-derived extracellular vesicles induce a tumor-like phenotype in normal recipient cells. J. Cell Physiol. 233, 6158-6172. doi: 10.1002/jcp.26464

Valadi, H., Ekstrom, K., Bossios, A., Sjostrand, M., Lee, J. J., and Lotvall, J. O. (2007). Exosome-mediated transfer of mRNAs and microRNAs is a novel mechanism of genetic exchange between cells. Nat. Cell Biol. 9, 654-659. doi: $10.1038 /$ ncb1596

Wennerberg, K., Rossman, K. L., and Der, C. J. (2005). The Ras superfamily at a glance. J. Cell Sci. 118, 843-846. doi: 10.1242/jcs.01660

Yanez-Mo, M., Siljander, P. R., Andreu, Z., Zavec, A. B., Borras, F. E., Buzas, E. I., et al. (2015). Biological properties of extracellular vesicles and their physiological functions. J. Extracell. Vesicles 4, 27066. doi: 10.3402/ jev.v4.27066

Yuana, Y., Sturk, A., and Nieuwland, R. (2013). Extracellular vesicles in physiological and pathological conditions. Blood Rev. 27, 31-39. doi: 10.1016/j.blre.2012.12.002

Zhang, S., Dai, H., Zhu, L., Lin, F., Hu, Z., Jing, R., et al. (2018). Microvesicles packaging IL-1beta and TNF-alpha enhance lung inflammatory response to mechanical ventilation in part by induction of cofilin signaling. Int. Immunopharmacol. 63, 74-83. doi: 10.1016/j.intimp.2018.07.034

Zhou, X., Zhang, W., Yao, Q., Zhang, H., Dong, G., Zhang, M., et al. (2017). Exosome production and its regulation of EGFR during wound healing in renal tubular cells. Am. J. Physiol. Renal Physiol. 312, F963-F970. doi: 10.1152/ ajprenal.00078.2017

Conflict of Interest: The authors declare that the research was conducted in the absence of any commercial or financial relationships that could be construed as a potential conflict of interest.

Copyright (C) 2020 Urciuoli and Peruzzi. This is an open-access article distributed under the terms of the Creative Commons Attribution License (CC BY). The use, distribution or reproduction in other forums is permitted, provided the original author(s) and the copyright owner(s) are credited and that the original publication in this journal is cited, in accordance with accepted academic practice. No use, distribution or reproduction is permitted which does not comply with these terms. 